\title{
Gestão democrática e participativa na pedagogia da alternância: a experiência da Escola Família Agrícola (EFA) de Goiás
}

Resumo: Este artigo apresenta alguns apontamentos acerca das experiências de gestão democrática e participativa promovida pela Escola Família Agrícola de Goiás, que trabalha com a Pedagogia da Alternância. Trata-se de uma experiência alternativa de educação para o meio rural que se encontra em pleno desenvolvimento desde 1994. Além disso, apresento um balanço histórico desde sua gênese na França, a chegada no Brasil. Com isso, queremos provocar uma reflexão das possibilidades de uma educação diferenciada, alternativa e filosoficamente contra-hegemônica aos modelos de gestão padronizados por uma cultura apolítica, já que percebemos nas práticas dessa experiência a formação de uma cultura política que protagoniza os sujeitos. Palavras-chave: Gestão democrática. Pedagogia da alternância. Escola Família Agrícola.

\section{Introdução}

No bojo das lutas dos trabalhadores e trabalhadoras no campo, a educação de qualidade referendada como um direito de cidadania aparece como um dos componentes de reivindicação e em muitos lugares como experiência alternativa, gerida pelos próprios trabalhadores. Neste contexto encontram-se a Escola Família Agrícola (EFA) e a Casa Familiar Rural (CFR). Elas foram implantadas no Brasil na década de 1960, a partir de uma experiência iniciada na França e espalhadas pela Itália, Espanha e diversos países da África.

No Brasil, ao conjunto de EFAs e CFRs convencionou-se chamar Centros Familiares de Formação por Alternância (CEFFAs). Entre outros objetivos, os centros surgem como uma possibilidade de educação apropriada às necessidades sociais e históricas, a fim de minimizar o êxodo, desenvolver o campo, superar as condições de pobreza, abandono, entre outras mazelas existentes no campo, através de uma formação conscientizadora dos jovens e suas famílias junto às comunidades.

O CEFFA é uma Associação de Famílias, Pessoas e Instituições, que visa contribuir com o desenvolvimento sustentável, através da educação, num espírito de solidariedade, que busca facilitar os meios e os instrumentos de formação adequados ao

Claudemiro Godoy do Nascimento Doutorando em Educação na Universidade de Brasília Professor da Universidade Federal de Tocantinsclaugnas@uft.edu.br 
crescimento dos educandos/as, sendo estes os principais protagonistas da promoção e do desenvolvimento integral (profissional, intelectual, humano, social, econômico, ecológico, espiritual) e de todo o processo de formação, valorizando a realidade local.

O surgimento da nova proposta no Estado de Goiás, especificamente na cidade de Goiás, significou, para os trabalhadores rurais, o enfrentamento da crise educacional estabelecida para os camponeses, pois os mesmos não tinham condições de acessibilidade para as escolas no meio urbano. Além disso, a nova proposta educacional - Pedagogia da Alternância - buscou desde o princípio recriar o ethos perdido do homem do campo ao fazer a dialética entre ser humano e terra, terra e ser humano.

(1) Entende-se, aqui, por pedagogênese, o surgimento de uma nova experiência educacional e pedagógica que abarca toda uma realidade concreta de pessoas e sociedades. A Pedagogênese das Maison Familiales Rurales significa o surgimento da própria Pedagogia da Alternância como corpus de um novo paradigma alternativo e sensível aos apelos de uma realidade concreta, a saber: os trabalhadores/as rurais da França na década de 30. É neste contexto que surge a pedagogênese ou a gênese de uma nova Pedagogia apropriada e, posteriormente, aperfeiçoada a atender os filhos/as de camponeses/

(2) A terminologia Alternância surge pela primeira vez nos Estados Unidos, em1906, com a designação de "ritmo apropriado" e busca associar a formação geral com a formação profissional.

(3) Neste sentido, conferir Concagh (1989) que aborda a educação francesa abandonada pelo Estado e pela Igreja.

(4) Na França dos anos 30 do século $\mathrm{XX}$, os proprietários rurais continuavam a viver numa realidade de agricultura de subsistência com enfoques para a produção familiar. Conferir os estudos de Chartier (1982).

\section{O surgimento das Efas na França}

Todas as EFAs, entre elas, a Escola Família Agrícola de Goiás, utiliza-se da Pedagogia da Alternância que possui sua "pedagogênese" nos agricultores franceses da década de 30 do século passado. A Pedagogia da Alternância ${ }^{2}$ nasce na França em 1935³. Surge inicialmente com o nome de Maison Familiale Rurale (MFR) ou Casa Familiar Rural. A realidade europeia apresentava um profundo desenvolvimento do capitalismo industrial, bem como uma transformação da realidade agrária a partir do crescente processo de urbanização ocasionado pelo êxodo rural. Estes fatores determinavam o aumento da produtividade e da ampliação do mercado. A situação socioeconômica na França era de extremo abandono, principalmente, ao falar-se dos camponeses/as que viviam sob a égide do esquecimento pelo Estado ${ }^{4}$. Esquecidos pelo Estado em todos os seus direitos básicos fundamentais como habitação, saúde e educação.

Em relação à educação, os filhos(as) dos camponeses(as) franceses tinham duas opções: ficar na propriedade dos pais, com a família e trabalhando de sol a sol, ou de frio a frio, ou então ir para as cidades onde tinha escola pública, saindo da realidade familiar rural e cultural que os cercava até este momento. Na verdade, quase sempre a primeira opção era a mais comum já que manter filhos(as) na cidade significava gastos financeiros absurdos para a realidade campesina francesa. Assim, mantinham seus filhos e filhas sob as condições de analfabetismo. Alguns afirmam que os pais camponeses da França da década de 30 não queriam que seus filhos(as) fossem estudar na cidade por medo 
de voltarem renegando a cultura e a dura realidade do meio rural. Pode até ter acontecido tais motivações de ordem subjetiva, mas considerar-se-á que o motivo principal do não envio de adolescentes e jovens do meio rural francês para estudarem na cidade possui um fator puramente econômico. Neste sentido, Queiroz (1997, p. 41) afirma:

Os filhos de camponeses tinham que optar entre continuar os estudos e sair da família e do meio rural para as cidades ou permanecer junto à família e o trabalho rural e interromper o processo escolar. As famílias precisavam da presença e trabalho dos filhos e ao mesmo tempo não tinham condições de mantêlos nas cidades.

Dessa forma, iniciou-se gradativamente um processo de mobilização por parte dos camponeses(as) ligados ao sindicato ${ }^{5}$, juntamente, com setores da Igreja, a fim de pensar uma alternativa viável para que se pudesse resolver a problemática da educação no meio rural na França. Os desafios eram muitos diante da pobreza regional de uma pequena localidade no sudoeste da França. Sob a liderança de Jean Peyrat, presidente da Seção Sindical e do secretário, Padre Abbé Granereau ${ }^{6}$ (1885-1988), buscou-se mobilizar outros camponeses(as) a fim de obter iniciativas concretas que minimizassem a problemática da educação aproveitando o saber popular e a prática existente no meio rural daquela realidade o que exigia o desenvolvimento de uma formação técnica e integral para os jovens rurais.

Em relação ao problema da educação vivido pelos franceses, afirma o Padre Abbe Granereau (1969, p. 24 apud NOSELLA, 1977, p. 19)

O Estado, através de seus professores (as) do primário, salvo algumas maravilhosas exceções, não sabia mesmo o que dizer aos agricultores a não ser o seguinte: seu filho é inteligente; não pode ser deixado na roça [...] é preciso encaminhá-lo nos estudos [...] vencerá na vida melhor que seu pai [...] conseguirá uma boa posição social.

Segundo Chartier (1986), a primeira experiência das MFRs (ainda não possuía este nome) em 1935 tinha quatro estudantes e aconteceu da seguinte forma: os jovens ficavam reunidos por
(5) Em 1920 surge o Sindicato Central de Iniciativas Rurais (SCIR) formado, em sua maioria, por democratas cristãos franceses com o objetivo de defender a profissionalização da agricultura francesa e organizar os profissionais da agricultura a partir dos princípios do sindicalismo, do associativismo e do cooperativismo.

(6) Padre Abbe Granereau era filho de trabalhadores rurais franceses. 
(7) Segundo Nosella (1977, p. 36) "[...] o pessoal não foi mandado à Itália com o explícito propósito de se especializar em Escola-Família: porém, aconteceu que a Entidade italiana (AES), tendo contato com as Escolas-Família da Itália, achou interessante mandar os brasileiros estagiarem nestas escolas". (8) Foram organizados comitês locais nas cidades capixabas de Anchieta, Alfredo Chaves, Iconha, Piúma e Rio Novo do Sul. uma semana em estudos num local apropriado (Casa Paroquial do Padre Abbe Granereau). E, por três semanas, permaneciam na propriedade familiar.

O primeiro país fora da França a receber a experiência das MFRs foi a Itália. Lá a experiência surgiu no início da década de 60 com o seguinte nome: Scuola della Famiglia Rurale.

Em termos de metodologia elas adaptaram ao ambiente italiano a metodologia francesa. O relacionamento com os poderes públicos é grande, portanto certas facilitações são maiores. Os docentes, porém, muitos deles sendo funcionários do Estado, eram menos motivados do que os docentes franceses. É uma experiência que encontrou apôio na Igreja, mas nasceu diretamente pela ação de homens políticos: o inverso do que aconteceu na França. (NOSELLA, 1977, p. 30)

O processo de expansão foi fulminante como bem afirma Queiroz (1997, p. 48), e hoje existem mais de 450 Centros de Formação em Alternância na França.

\section{O surgimento das Efas no Brasil}

No Brasil, as primeiras experiências com a Pedagogia da Alternância surgiram em 1969, no Estado do Espírito Santo, município de Anchieta. Já em 1965-1966 iniciou-se uma movimentação a fim de estabelecer a colaboração - mediada pelo Padre Humberto Pietogrande - entre a Itália e o Brasil, especificamente no Estado do Espírito Santo onde se localiza a Província da Companhia de Jesus (Jesuítas). Neste sentido, foram tomadas algumas iniciativas como: a Fundação da Associazione degli Amici dello Stato Brasiliano dello Spirito Santo (AES) em 11 de dezembro de 1966, o envio de jovens brasileiros para estudarem na Itália ${ }^{7}$, a visita de técnicos italianos ao Brasil e a constituição de comitês locais ${ }^{8}$.

Assim, através da fundação do Movimento Educacional e Promocional do Espírito Santo (MEPES), aos 25 de abril de 1968 surge a primeira experiência de Pedagogia da Alternância no Brasil com o nome de Escola Família Agrícola (EFA). Elas surgem no Brasil a partir da experiência italiana e do intercâmbio com a Argentina. Portanto, a 9 de março de 1969 inicia-se a primeira experiência educativa com a implantação da Escola Família Agrí- 
cola de Olivânia - ES, entre os municípios de Anchieta e Alfredo Chaves. Neste mesmo ano, iniciam-se as atividades da Escola Família Agrícola de Rio Novo do Sul - ES. Em 1971 surge a Escola Família de Campinho, localizada no município de Iconha.

Com a expansão das Escolas Famílias no Espírito Santo, viuse necessidade de formação para os monitores(as) para que pudessem estar se formando e conhecendo a Pedagogia da Alternância. Essa formação deveria acontecer no Brasil, já que na Itália era inviável devido aos problemas de adaptação a posteriori.

Logo após a abertura das primeiras escolas, em vista de uma expansão de novas escolas e por causa da saída constante de monitores, sentiu-se a necessidade de formar novo pessoal para Escolas [...] Além dessas razões (prática e pedagógica) reparouse que o pessoal treinado na Itália [...] parecia sofrer um processo de alienação notável, tornando-se a inserção na região do MEPES técnica e psicologicamente problemática. (NOSELLA, 1977, p. 42-43)

Atualmente, existem no Brasil mais de 200 Centros Educativos em Alternância, em 18 Estados ${ }^{9}$. Apesar das diferenças, inclusive no nome (Escola Família Agrícola, Casa Familiar Rural, Escola Comunitária Rural), todos eles têm em comum a Pedagogia da Alternância.

Segundo dados da UNEFAB, existem em torno de 112 EFAs, sem contar as Casas Familiares Rurais e as Escolas Comunitárias Rurais, em funcionamento e 40 sendo implantadas em todo o território brasileiro. A Pedagogia da Alternância é adotada por três modelos diferentes com objetivos diferenciados, são elas: as Escolas Famílias Agrícolas (EFAs), as Escolas Comunitárias Rurais (ECRs) e as Casas Familiares Rurais (CFRs).
(9) A União Nacional das Escolas Famílias Agrícolas no Brasil (UNEFAB), criada em 1982, com sede atualmente em Brasília - DF, é a entidade representativa das Escolas Famílias Agrícolas no Brasil. Existe, a nível internacional, a Associação Internacional das Escolas Famílias Agrícolas (AIMFR), com sede em Paris, França. 
Quadro 1: Diferenças entre os três modelos de CEFFAs existente no Brasil Fonte: Nascimento (2005, p. 46).

\begin{tabular}{|c|c|c|}
\hline \multicolumn{3}{|c|}{ CENTROS FAMILIARES DE FORMAÇÃO POR ALTERNÂNCIA - CEFFAs } \\
\hline EFAs & CFRs & ECRs \\
\hline Enfatiza a formação & As CFRs têm como & Estão localizadas ao Norte do \\
\hline escolar dos educandos(as) & prioridade a formação & Espírito Santo - ES, e também na \\
\hline a partir do regime seriado & técnica do educando(a). & Bahia existem muitas experiências. \\
\hline e regularizado junto às & Diferenciam-se das & Possuem as mesmas características \\
\hline Secretarias Estaduais de & EFAs por adotar o & metodológicas das EFAs, no \\
\hline Educação (SEE), & regime de suplência. & entanto, são grupos autônomos que \\
\hline $\begin{array}{l}\text { possuindo também a } \\
\text { formacão técnica tanto }\end{array}$ & $\begin{array}{l}\text { Existem casos do jovem } \\
\text { permanecer duas }\end{array}$ & $\begin{array}{l}\text { estão ligados a movimentos sociais } \\
\text { e eclesiais que pressionam o poder }\end{array}$ \\
\hline no Ensino Fundamental, & semanas na Escola e & local para realizar a implantação e \\
\hline bem como de forma & uma semana na família. & a aprovação da Pedagogia da \\
\hline mais específica, no & Por isso, em grande & Alternância, para que a \\
\hline Ensino Médio onde se & parte, a denominação de & experiência possa ter validade. Por \\
\hline trabalha a Educação & Casa Familiar Rural. & isso, muitas experiências surgem \\
\hline $\begin{array}{l}\text { Profissional de Técnico } \\
\text { em Agropecuária. }\end{array}$ & & $\begin{array}{l}\text { com o apoio das prefeituras locais, } \\
\text { bem como do Governo do Estado. }\end{array}$ \\
\hline
\end{tabular}

As principais características das Casas Familiares Rurais ou Escolas Famílias Agrícolas são: a responsabilidade das famílias na gestão por meio de uma Associação de Pais e Alunos/as; a alternância dos períodos entre o meio de vida socioprofissional e a Casa Familiar onde o educando(a) exerce na prática uma concepção dialética de formação; a vida dos educandos/as em pequenos grupos e em internatos; uma equipe de formadores/as denominadas de monitores(as), e uma pedagogia adaptada (CHARTIER, 1985) que se chama Pedagogia da Alternância.

Nessas principais características da Casa Familiar/Escola Família Agrícola, percebe-se a diferença com as outras escolas rurais. Diferentemente destas, as CFR/EFAs/ECR têm o seu currículo todo voltado para a realidade rural em que vivem as famílias dos alunos(as). Os pais são chamados a participar de toda a vida da escola, desde o acompanhamento integral dos filhos(as) quando estão junto à família até na administração, coordenação e manutenção da escola.

\section{Alternância e gestão democrática: participar é preciso na Efa de Goiás}

Na cidade de Goiás é onde se encontra implantada a Escola Família Agrícola de Goiás. É uma cidade pacata e tradicional onde sobrevive o último reduto dos antigos coronéis e da velha oligarquia rural. As famílias, por meio das representações simbólicas de poder, exercem uma forte influência na mentalidade das pessoas. Mesmo quando o Município de Goiás começou a sofrer as ocupações de terra na década de 80, as famílias que descendem do velho 
coronelismo proveniente dos bandeirantes continuavam criando relações de subordinação com as classes subordinadas da cidade.

O Município de Goiás possui uma área de 3.118,8 km². Possui uma densidade demográfica de $8,7 \mathrm{hab} / \mathrm{km}^{2}$. A altitude da sede, ou seja, a cidade de Goiás, é de 496 m. A data de sua fundação oficial registra-se como sendo o ano de 1736. Está localizada a uma distância de 125,6 Km da capital do Estado, a cidade de Goiânia. O Município de Goiás pertence à microrregião denominada Rio Vermelho, que abrange os seguintes municípios: Goiás, Araguapaz, Faina, Itapirapuã, Matrinchã, Jussara, Aruanã, Britânia e Santa Fé de Goiás. A cidade de Goiás pertence a uma mesorregião denominada Noroeste Goiano.

Utilizando-se da Pedagogia da Alternância, a EFA de Goiás, mesmo com as dificuldades, encontra-se na contramão da história, exercendo um papel de sujeito da história com vários atores em potencial. Não se pode negar que a Escola Família Agrícola de Goiás é uma tentativa de mostrar à realidade local uma resistência cultural a partir da vida e da luta dos camponeses(as) que fizeram a história acontecer. Neste sentido, afirma veemente o grande educador de Guiné Bissau Amílcar Cabral (apud FREIRE, 1977, p. 90):

\begin{abstract}
A luta de libertação, que é a expressão mais complexa do rigor cultural do povo, de sua identidade e de sua dignidade, enriquece a cultura e lhe abre novas perspectivas de desenvolvimento. As manifestações culturais adquirem conteúdo novo e novas formas de expressão. Tornam-se assim um instrumento poderoso de informação e de formação política, não somente na luta pela independência, mas ainda na batalha maior pelo progresso [...] a dinâmica da luta exige a prática da democracia, da crítica e da autocrítica, a crescente participação das populações na gestão de sua própria vida, a alfabetização, a criação de escolas e serviços sanitários, a formação de quadros extraídos dos meios camponeses e operários, e outras tantas realizações que implicam em grande aceleração do processo cultural da sociedade. Tudo isso torna claro que a luta pela libertação não é apenas um fato cultural, mas também um fator de cultura.
\end{abstract}

Segundo Boneti (2000, p. 237-238), o papel da escola hoje pode ser sintetizado em três grandes eixos transformadores, a saber: a organização da sociedade civil, a formação do sujeito social e o 
(10) Segundo Cury, não podemos confundir consilium com concilium, que significa convocação, assembleia, concílio. fortalecimento do local em contraposição ao global. Nesta direção, Melo (2000, p. 252-253) afirma que "[...] a escola tem um papel fundamental nesse processo de transformação, que resgata inicialmente as nossas referências coletivas e a convicção de que podemos intervir no processo de construção histórica da sociedade."

Os atores sociais da Escola Família Agrícola de Goiás são os agentes que constroem o cotidiano vivenciado nas experiências educativas, políticas e sociais. São eles: educandos(as), monitores(as), pais e mães, parceiros(as) e outros chamados de companheiros(as) da caminhada. Estes vivenciam os eixos norteadores apresentados por Boneti o que implica a construção de uma escola que consegue realizar uma intervenção concreta na realidade onde se encontra, a saber: nos assentamentos rurais de onde são provenientes os educandos e famílias que compõem a EFA de Goiás.

A Associação é um dos pilares da EFA. É a gestão educacional realizada pelos atores provenientes das comunidades que também assumem determinados costumes e hábitos da sociedade capitalista e o reproduzem em suas práticas de gestão. Atualmente, os pais que participam do Conselho são provenientes, em sua grande maioria, da luta pela terra e são lideranças em suas comunidades nos assentamentos. Em sua grande maioria não possuem formação escolar, mas sabem ler o mundo dos signos e simbolizam bem esta ótica na prática.

Neste sentido, Cury realiza uma abordagem necessária para que possamos compreender o significado de Conselho e suas especificidades.

\footnotetext{
Conselho vem do latim Consilium ${ }^{10}$. Por sua vez, consilium provém do verbo consulo/consulere, significando tanto ouvir alguém quanto submeter algo a uma deliberação de alguém, após uma ponderação refletida, prudente e de bom senso. Conselho é também o lugar onde se delibera. Deliberar implica a tomada de uma decisão, precedida de uma análise e de um debate que, por sua vez, como se viu, implica a publicidade dos atos na audiência e na visibilidade dos mesmos. (CURY, 2000, p. 47-48)
}

Assim, podemos concluir a definição acerca do Conselho como sendo "o lugar onde a razão se aproxima do bom senso e ambos do diálogo público, reconhecendo que todos são intelectuais, ainda que nem todos façam do intelecto uma função permanente". 
(CURY, 2000, p. 50) O Conselho da EFA de Goiás se reúne ordinariamente a cada bimestre e extraordinariamente sempre que convocada por um terço de seus membros. Ao todo são 12 traba1hadores rurais (pais e mães) que representam as comunidades, um representante de cada turma de educandos (da $5^{\text {a }}$ série ao $3^{\text {a }}$ ano do Ensino Médio) totalizando sete educandos/as e um representante dos educadores juntamente com a Direção e Coordenação Pedagógica da EFA, ou seja, três educadores. Ao todo, o Conselho da Associação está composto por 22 membros com voz e vez e direito deliberativo. Neste sentido, concordamos que as palavras de Cury representam o que há de mais genuíno na gestão democrática da EFA de Goiás.

A gestão democrática é também a presença no processo e no produto de políticas do governo. Os cidadãos querem mais do que ser executores de políticas, querem ser ouvidos e ter presença nos momentos de elaboração. Sinais desse tipo de presença são os chamados orçamentos participativos de muitos municípios. (CURY, 2000, p. 55)

O Conselho Administrativo não é a instância máxima da Associação. A Assembleia Geral da Associação, que acontece uma vez por semestre, é o organismo máximo de deliberação da EFA e é composta por todos os pais e mães (trabalhadores rurais), por todos os educandos e por todos os educadores. No dia a dia, o Consetho que representa a Associação e é composto pelo Presidente, o Secretário e o Tesoureiro, que são sempre os próprios pais e mães de educandos da EFA, ou seja, trabalhadores rurais. A organização da EFA de Goiás apresenta evidentemente conflitos cotidianos que são sempre superados pela solidariedade de todos e todas que participam do processo. Mas, o mais interessante é a corresponsabilidade de todos para com a administração da escola. Todos se preocupam. Todos participam. Muitas vezes, os jovens do Ensino Médio conseguem se unir para fazer reivindicações de melhorias para a escola e fazem argumentações que impressionam a todos os trabalhadores rurais que, contentes, sentem-se realizados pelo crescimento intelectual e profissional de seus filhos e filhas.

Há uma forte cultura de participação por parte dos pais e mães de educandos/as da EFA de Goiás. Ainda na visão de Cury (2000, p. 51), "[...] participar é dar parte e ter parte. O primeiro 
movimento visa informar, dar publicidade, e o segundo é estar presente, ser considerado um parceiro nas grandes definições de uma deliberação ou de um ordenamento".

Para Gramsci (2001, p. 35), "[...]o dirigente deve ter aquele mínimo de cultura geral que lhe permita, se não "criar" autonomamente a solução justa, pelo menos saber julgar entre as soluções projetadas pelos especialistas e, conseqüentemente, escolher a que seja justa do ponto de vista "sintético" da técnica política."

A Gestão da Escola Família Agrícola de Goiás é feita pela Associação de Pais e Alunos. Significa que na EFA a família se responsabiliza pela educação de seus filhos(as). A Assembleia é a instância máxima da Associação. Nessas reuniões decidem-se os pais que serão responsáveis pela Gestão e farão parte do Conse1ho Administrativo (mandato de dois anos). Nesta concepção de gestão, concordamos que a EFA de Goiás entende gestão a partir de um conceito determinado.

Gestão é administrar, é tomada de decisão, é organização, é direção. Relaciona-se com a atividade de impulsionar uma organização a atingir seus objetivos, cumprir sua função, desempenhar seu papel. Constitui-se de princípios e práticas decorrentes que afirmam ou desafirmam os princípios que as geram. Estes princípios, entretanto não são intrínsecos à gestão como a concebia a administração clássica, mas são princípios sociais, visto que a gestão da educação se destina à promoção humana. A gestão da educação é responsável por garantir a qualidade de uma mediação no seio da prática social global, que se constitui no único mecanismo de hominização do ser humano, que é a educação, a formação humana de cidadãos. (FERREIRA, 2000, p. 306-307)

Os monitores(as) da Escola Família Agrícola de Goiás compreendem a concepção de educação como ato de preparação para a vida vivida com consciência, criticidade, solidariedade, etc. Formar os educandos(as) com espírito de sabedoria para serem futuras lideranças nas comunidades. É o ato de ensinar e aprender com o mundo, a sociedade e os saberes que estão presentes nas pessoas, nas comunidades, na cultura e na memória coletiva daqueles(as) que lutaram pela terra e por dignidade no meio rural. A educação para os monitores(as) deve valorizar e despertar nos educandos(as) a busca pelo conhecimento que transforma 
constantemente o ser humano em agente crítico, na concepção gramsciana, em agente orgânico que cria e recria a sociedade numa dialética histórica constante. Neste sentido, estão buscando cumprir o que ficou determinado pelo Projeto Político-Pedagógico construído em forma de rede de retalhos, a várias mãos. Daí que concordamos novamente com Bordignon e Gracindo, pois percebemos que o Projeto Político-Pedagógico da EFA de Goiás abarca as duas concepções apontadas por estes autores, a saber: a política e a pedagógica.

Pensar e construir uma escola é, essencialmente, colocar em prática uma concepção política e uma concepção pedagógica que se realimentam e que se corporificam na sua Proposta Político-Pedagógica. Concepção política, porque ela é que promove a ação transformadora da sociedade, e concepção pedagógica, porque é ela o substrato da função escolar. A estrutura e os demais meios são estabelecidos e organizados em função desse projeto. Dessa forma, as diversas facetas da gestão têm um foco privilegiado que determina sua finalidade principal (pedagógica) assentadas em açõesmeio (pessoal, material, patrimônio, financeira etc.) que viabilizam sua finalidade. (BORDIGNON; GRACINDO, 2000, p. 154)

Significa, também, apropriar-se de determinados conhecimentos empíricos e teóricos adquiridos e relacionados com a vida. Adquire-se educação, portanto, na família, no meio e, ainda, na escola. São nestes três ambientes que se dá a formação da pessoa humana. Por isso, está bem claro para os monitores(as) da Escola Família Agrícola de Goiás que educação não se reduz a escola.

Os monitores(as) compreendem muito bem o conceito de cultura e sabem que estão formando uma forte cultura política nas consciências dos educandos(as). Na EFA de Goiás, busca-se, neste sentido, valorizar e respeitar as diferentes culturas, principalmente as minorias que juntas são a grande maioria da população brasileira e mundial, entendidos aqui como sendo a grande massa de excluídos(as).

A Pedagogia da Alternância busca em seus objetivos, na EFA de Goiás, recriar a cultura e a identidade dos camponeses(as) por meio das visitas as famílias, do diálogo e da valorização/respeitabilidade por parte de todos(as) com a cultura. A EFA, por meio da Pedagogia da Alternância, propicia criar culturas de participação, 
do diálogo e da cooperação coletiva. Assim, se desperta nos educandos(as) aquilo que estava adormecido.

A educação pensada e refletida pela Pedagogia da Alternância, bem como, suas práticas educativas acontecem na escola, nas famílias, comunidades, ONG, organizações sindicais, entidades de classes, nas igrejas e manifestações religiosas, nas formações dos movimentos sociais, nos acampamentos e nos projetos de assentamentos.

Assim, as práticas educativas da Escola Família Agrícola de Goiás acontecem, segundo a concepção de seus atores, na vida, no cotidiano, nas lutas. Para Gohn (2001, p. 100), a educação apresenta três dimensões que se percebem introjetadas nas práticas e nas concepções dos agentes orgânicos da EFA de Goiás. A família é caracterizada como espaço de educação informal que acontece "nos processos espontâneos ou naturais, ainda que seja carregada de valores e representações, como é o caso da educação familiar". A educação não-formal se dá na "intencionalidade de dados sujeitos em criar ou buscar determinadas qualidades e/ou objetivos". Neste sentido, a educação não-formal está presente nos movimentos sociais do campo, nas associações e cooperativas dos assentamentos, nas organizações, nas igrejas, nos sindicatos, nos partidos políticos e em toda a sociedade. Já a educação formal se limita ao espaço e concepção do processo ensino-aprendizagem da unidade escolar. Pode-se afirmar que a EFA de Goiás, por meio da Pedagogia da Alternância, assimila estas três dimensões da educação.

O mais importante disso tudo é que recentemente o CEFFA proporcionou a aprovação da Pedagogia da Alternância como modelo de educação para as escolas do campo. Trata-se do Parecer do CEB n ${ }^{0} 1 / 2006$, do Conselho Nacional de Educação, aprovado em 1/2/2006, que recomenda a adoção da Pedagogia da Alternância em Escolas do Campo.

Os CEFFA cumprem as exigências legais quanto à duração do ano letivo, pois integram os períodos vivenciados no centro educativo (escola) e no meio sócioprofissional (família/comunidade), considerando como dias e horas letivos atividades desenvolvidas fora da sala de aula, mas executadas dentro do Plano de Estudo de cada aluno. Recomenda-se que o Projeto Político-Pedagógico de 
cada CEFFA adote as características da Pedagogia da Alternância na concepção de alternância formativa, isto é, alternância integrativa real ou copulativa, de forma a permitir a formação integral do educando, inclusive para prosseguimento de estudos, e contribuir positivamente para o desenvolvimento rural integrado e auto-sustentável, particularmente naquelas regiões/localidades em que prevalece a agricultura familiar.

A Pedagogia da Alternância se apresenta como um sistema de ensino alternativo, eficaz e que consegue fazer uma profunda relação dialética entre escola-família. Mas, o maior tesouro da EFA de Goiás é sua gestão democrática e participativa. Pais e mães coordenando o cotidiano da escola em conjunto com os educadores e com os próprios educandos e educandas. De sem voz e sem vez a sujeitos coletivos com voz e vez desde a elaboração do Projeto Político-Pedagógico aprovado em Assembleia com todos os atores ao dia a dia da escola onde se vê uma gestão compartilhada e corresponsável, pois todos são chamados a construir e manter esse sonho e essa esperança de se ter uma educação que realmente atende aos anseios desses sujeitos históricos que constroem seus espaços de liberdade e de cidadanização.

\section{Considerações finais}

Falar hoje de Escola Família Agrícola significa a abordagem de uma alternativa. A EFA de Goiás apresenta determinadas práticas educativas a partir tentativa de se implantar a Pedagogia da Alternância. A experiência de educação apresentada pela EFA de Goiás diante de sua história e de sua atual postura condiz como proposta alternativa que se constrói como uma escola de resistência. Também, num universo teórico, toda e qualquer EFA se apresenta como sendo um novo paradigma para a educação no meio rural. Mas, especificamente, na EFA de Goiás a experiência de alternância em alguns momentos se apresenta como espaço de resistência e de recriação da cultura.

Podemos afirmar que a Escola Família Agrícola de Goiás é uma tentativa em fase a ser superada, pois se encontra em sua adolescência. O que importa é que a experiência foi implantada e que seus atores devem aprender a ser mais resistentes e recriadores de uma cultura política e pedagógica diferenciada o que irá deter- 
minar com que a Escola se torna também o arquétipo dos próprios sujeitos que aí se encontram.

Assim, a luta por uma educação básica própria aos camponeses(as) deve tomar um rosto de resistência cultural ativa. A Pedagogia da resistência nos gestos e no fazer funcionar a escola mesmo sem dinheiro, bem como na ocupação das Prefeituras das cidades, a fim de reivindicar melhores condições da estrada. Pedagogia da Resistência quando se vê camponeses(as) atuando na gestão administrativa de uma escola que lhes pertence. Eles devem fazer parte desta ciranda e ter a consciência de que não se pode reproduzir a mesma lógica neoliberal de relação entre opressor-oprimido para dentro da escola senão perder-se-á as condições reais de existência de uma Pedagogia da Alternância como sendo a Pedagogia da Resistência Cultural. A EFA de Goiás é uma semente que foi lançada ao solo fértil de Goiás. Não se pode perder a colheita da semente plantada que morreu e se tornou fruto.

A existência da Escola Família Agrícola de Goiás torna-se história. Nunca morrerá. Seus atores sempre serão lembrados por realizar um projeto alternativo. Portanto, a EFAGO poderia ser definida como um projeto alternativo pedagogicamente conscientizador, sociologicamente comprometedor, filosoficamente formativo, culturalmente resistente, politicamente democrático e religiosamente ecumênico. De fato, diante dessas definições não nos resta duvidar da sua importância, necessidade e urgência. Resta-nos, por fim, compreender os fenômenos construídos pelos sujeitos históricos em constante movimento.

Democratic and participatory management in the pedagogy of alternation: the experience of the School Family Fund (EFA) from Goiás

\begin{abstract}
This article presents some notes concerning the experiences of democratic and participative management promoted by the School Agricultural Family of Goiás that works with the Pedagogy of the Alternation. One is about an alternative experience of education for the agricultural way that if finds in full development since 1994. Moreover, I present a historical rocking since its gênese in France, the arrival in Brazil. With this, we want to provoke a reflection of the possibilities of a differentiated, alternative and with a philosophy against-hegemonic education to the standardized models of management for a non-political culture, since we perceive in practical of the this experience formation of a culture politics that carries out the citizens.

Keywords: Democratic management. Pedagogia of the Alternation. Schools Agricultural Families.
\end{abstract}




\section{Referências}

ALMEIDA, Luisa Maria. Ribeiro. O plano de estudo da Escola Família Agrícola (EFA) de Goiás. Goiânia: UFG, 1998.

BONETI, Lindomar W. As políticas educacionais, a gestão da escola e a exclusão social. In: FERREIRA, Naura Syria Carapeto; AGUIAR, Márcia Ângela da S. Gestão da educação: impasses, perspectivas e compromissos. São Paulo: Cortez, 2000.

BORDIGNON, Genuíno; GRACINDO, Regina Vinhaes. Gestão da educação: o município e a escola. In: FERREIRA, Naura Syria Carapeto; AGUIAR, Márcia Ângela da S. Gestão da educação: impasses, perspectivas e compromissos. São Paulo: Cortez, 2000.

CHARTIER, D. Motivation et alternance. Paris: Universitaires, 1982. (Collection Mésonance)

La spécificité des maisons familiales rurales d'éducation et d'orientation. Revue Française de Pédagogie, n. 73, p. 23-30, oct.-nov.déc. 1985.

A $l$ 'aube des formations par alternance. Paris: Universitaires, 1986. (Collection Mésonance).

CONCAGH, Viviane Bosi. A escola família agrícola no Espírito Santo. Cadernos de Pesquisas, São Paulo, n. 68, p. 89-98, fev. 1989.

CURY, Carlos Roberto Jamil. Os conselhos de educação e a gestão dos sistemas. In: FERREIRA, Naura Syria Carapeto; AGUIAR, Márcia Ângela da S. Gestão da educação: impasses, perspectivas e compromissos. São Paulo: Cortez, 2000.

FERREIRA, Naura Syria Carapeto. Gestão democrática da educação: ressignificando conceitos e possibilidades. In: FERREIRA, Naura Syria Carapeto; AGUIAR, Márcia Ângela da S. Gestão da educação: impasses, perspectivas e compromissos. São Paulo: Cortez, 2000.

FRANCO, Maria Laura P.B.; ZIBAS, Dagmar M.L. Educação-produção: as distorções do sistema. Educação e Sociedade, n. 29, p. 100121, jul. 1988.

FREIRE, Paulo. Cartas à Guiné-Bissau: registros de uma experiência em processo. Rio de Janeiro: Paz e Terra, 1977.

Pedagogia da autonomia: saberes necessários à prática educativa. 24. ed. Rio de Janeiro: Paz e Terra, 1996.

GIANORDOLI, Regina Lúcia. Nova perspectiva para a educação rural: pedagogia da alternância. Dissertação (Mestrado) - Faculdade de Educação, Pontificia Universidade Católica, Rio de Janeiro, 1980.

GOHN, Maria da Glória. Educação não-formal e cultura política. 2. ed. São Paulo, Cortez, 2001. 
GRAMSCI, A. Cadernos do cárcere. 2. ed. Rio de Janeiro: Civilização Brasileira, 2001. v.2

HABERMAS, Jürgen. Teoría de la ación comunicativa. Madri: Taurus, 1985.

MELO, Maria Teresa Leitão de. Gestão educacional: os desafios do cotidiano escolar. In: FERREIRA, Naura Syria Carapeto; AGUIAR, Márcia Ângela da S. Gestão da educação: impasses, perspectivas e compromissos. São Paulo: Cortez, 2000.

MOVIMENTO DE EDUCAÇÃO PROMOCIONAL DO ESPIRITO SANTO. Uma cultura nova para um mundo novo. Vitória: ES, 1976.

Documentário, apresentado no II ${ }^{\circ}$ Simpósio de Educação Rural do Espírito Santo. Mimeografado.

NASCIMENTO, Claudemiro G. A educação camponesa como espaço de resistência e recriação da cultura: um estudo sobre as concepções e práticas educativas da Escola Família Agrícola de Goiás - EFAGO. 2005. Dissertação (Mestrado) - Faculdade de Educação, Universidade de Campinas, 2005.

Pedagogia da resistência cultural: um pensar a educação a partir da realidade campesina. Goiânia: UEG, 2003. Trabalho apresentado no VIII Encontro Regional de Geografia do Centro-Oeste, 2003.

NOSELlA, Paolo. Uma nova educação para o meio rural. 1977. Dissertação (Mestrado) - Pontifícia Universidade Católica, São Paulo, 1977.

PESSOTI, Alda L. Escola família agrícola: uma alternativa para o ensino rural. 1978. Dissertação (Mestrado) - Fundação Getúlio Vargas, Rio de Janeiro, 1978.

PINTO, Ana Maria P. O Plano de Formação no Processo Pedagógico em Alternância. Brasília, DF.: UNEFAB, 2001. Mimeografado.

QUEIROZ, João B. P. O processo de implantação da Escola Família Agrícola (EFA) de Goiás. 1997. Dissertação (Mestrado) - Universidade Federal de Goiás, 1997.

UNIÃO NACIONAL DAS ESCOLAS DE FAMÍLIAS AGRÍCOLAS DO BRASIL. Agenda das EFAs. [Anchieta: ES.], 2002. 